Article

\title{
An Employee's Living Wage and Their Quality of Work Life: How Important Are Household Size and Household Income?
}

\author{
Stuart C. Carr *, Jarrod Haar *, Darrin Hodgetts, James Arrowsmith, \\ Jane Parker, Amanda Young-Hauser, Siautu Alefaio-Tuglia, Harvey Jones \\ Project GLOW (Global Living Organizational Wage), EPIC (End Poverty \& \\ Inequality Cluster), Auckland, 1311, New Zealand \\ * Correspondence: Stuart Carr, Email: S.C.carr@massey.ac.nz; \\ Jarrod Haar, Email: jarrod.haar@aut.ac.nz.
}

\begin{abstract}
Living Wage (LW) campaigns normally assume a prototype household configuration in setting their LW rate, comprised of number of dependent householders and the number of incomes. This information is used to calculate the hourly pay rate required to sustain their quality of life and work life. Real households are nonetheless diverse in terms of number of householders and incomes, rendering the living wage conceptually more of a continuous variable than a single constant, across a wage spectrum. We explored this spectrum and its links to job attitudes with a nationally representative sample of $N=1011$ low-waged New Zealanders. We measured each participant's: hourly pay rate, number of household dependents and total household income, alongside individual job attitudes indicative of quality of work life (job satisfaction, work engagement, career satisfaction, meaningful empowerment, affective commitment, organizational citizenship behaviours and work-life balance). As a set, job attitudes consistently pivoted upwards into positive values approximating the campaign LW rate in New Zealand, regardless of either number of household dependents or household income (net of personal wage). However household income net of personal wage (unlike number of household dependents) buffered the gradient of the pivot upwards. The gradient was steeper (more clearly transformational and binary) among lowest-waged workers, in single-income households. To the extent that job attitudes as a set are already widely linked to individual and unit-level productivity, paying at or above the living wage threshold may bring productivity gains and thereby contribute toward decent work and economic development combined.
\end{abstract}

\section{Gopen Access}

Received: 10 May 2019

Accepted: 19 June 2019

Published: 21 June 2019

Copyright (C) 2019 by the author(s). Licensee Hapres, London, United Kingdom. This is an open access article distributed under the terms and conditions of Creative Commons Attribution 4.0 International License.

KEYWORDS: living wage; working poverty; New Zealand; decent work; job attitudes 


\section{INTRODUCTION}

At the recent centenary of the International Labour Organization (ILO), the ILO's Global Commission on the Future of Work recommended a universal labour guarantee, including a "living wage" [1]. This concept of a living wage is not just pecuniary and material but also extends to meeting people's aspirations for a decent quality of life (and work life), being productive (at work), and enabling shared prosperity at home and across future generations [2]. It is thus central to the United Nations Sustainable Development Goals (SDGs), which aim to eradicate poverty in all its forms everywhere, and especially SDG 8-Decent Work and Economic Growth [3].

Living wage campaigns have proliferated since the 1990s, partly in response to a growing failure of legal Minimum Wages to prevent working poverty [3]. Globally, there are now more than seven times more people in work and in "vulnerable employment", with more again in work that is "precarious" [4,5]. Shared prosperity is anathema to income inequality, which has grown "in nearly all countries" [6]. Wage-related inequality within workplaces, a product of high and low wages, might be part responsible for falling per capita productivity globally [7], even in relatively dynamic regions like Asia-Pacific [8]. This paper explores possible linkages between living wage thresholds, quality of (work) life, and productivity, in one Asia-Pacific economy, New Zealand (NZ).

An intellectual context for this paper is the continuing debate between advocates of growth through everyday wages that are lower, versus higher [9]. Much of the available evidence remains inconclusive to either side, partly perhaps because it tends to rely on single data points (i.e., a specific living wage figure), rather than a variable (multiple wage values along a wage spectrum): As we have argued elsewhere, in theory the living wage is an empirically determinable point of inflexion, or pivot from along a wage and income continuum, where wage covers not only the material cost of living, such as food and shelter, but also one's quality of living, including quality of work life [10,11]. Setting "a" living wage is thereby important towards creating the possibility of escaping from working poverty traps, and for cultivating climates of work justice and work-life balance [12,13]. Setting "the" right living wage, in terms of money, is crucial because too low means that escape from poverty may not actually be possible whilst setting it unaffordably high undermines organizational viability rather than sustainability [9]. Such theoretical links between wages and quality of living are given in Figure 1. 


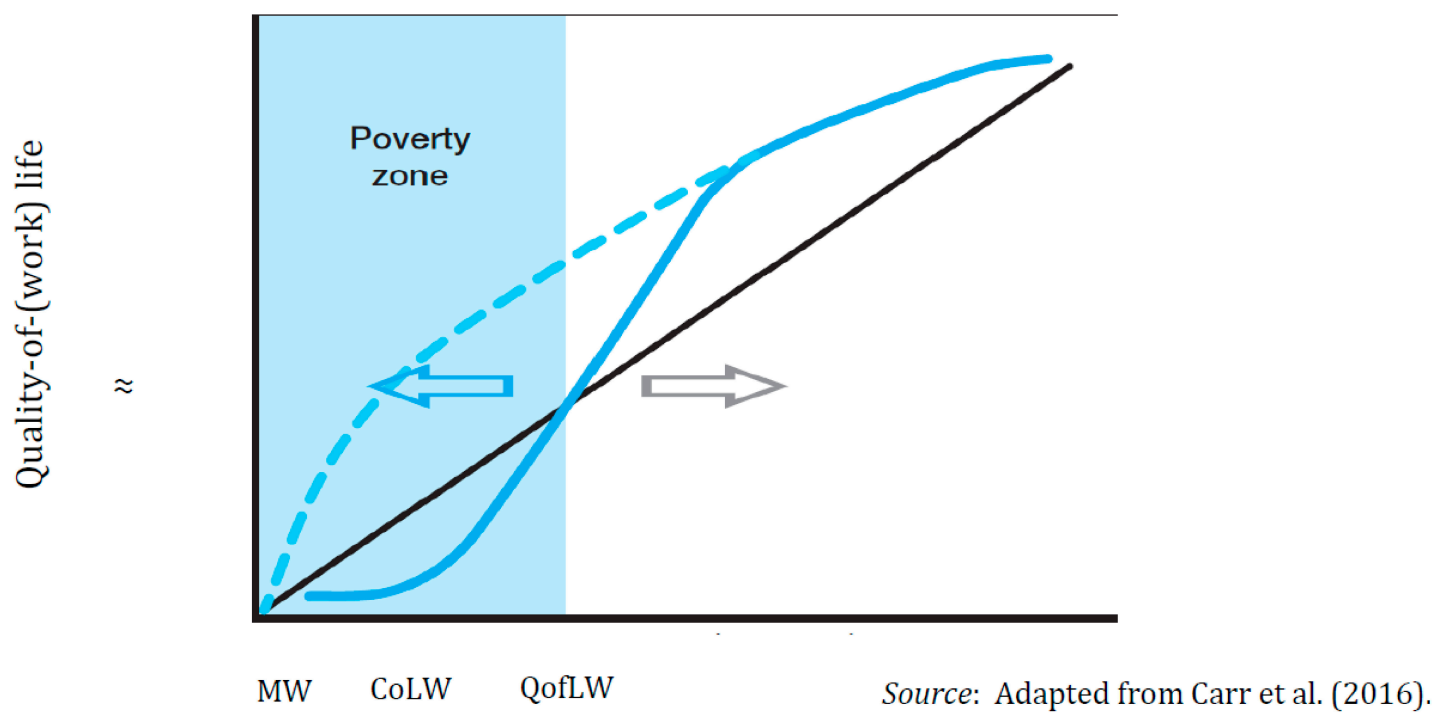

Wage and Income

Figure 1. Quality of (work) life along the Wage and Income spectrum. Key: MW = Legal Minimum Wage; CoLW = Cost-of-Living Wage; QoLW = Quality-of-Living Wage; $\approx$ = balance in quality of (work) life. Adapted with permission from Carr et al. [10].

Intuitively, Figure 1 positions commonly used wage descriptors along a Wage and Income spectrum, operationalising a wages and incomes as a variable. Thus the legal Minimum Wage (MW) is often less than the actual monetary Cost of Living Wage (CoLW) that would in turn allow people to eat and subsist materially; whilst a Quality of Living Wages (QoLW) aspires to capabilities like participation in society and social life, for example, and thus would theoretically aim higher-and closer to the ILO Agenda for enabling Decent Work (under SDG-8, above).

Figure 1 also makes competing theoretical predictions (the black line was included in Carr et al. [10] for comparison only). The continuous blue line is predicting a poverty trap in the blue zone, whereby quality of (work) life as a function of income is non-linear due to workers feeling trapped below the poverty line until some living wage threshold is crossed, whilst the dotted line implies that even very low wages can be positive (i.e., any wage is a good wage, especially compared to being unemployed, even in economies with social welfare). Examples for how a poor quality of life manifests at work (i.e., on the $y$-axis in Figure 1) include job attitudes, for instance, poor job satisfaction and workplace disengagement, low organizational commitment, work-life imbalance, and a sense of disempowerment [10]. According to Figure 1, only beyond a certain Quality-of-Living Wage (QoLW) threshold [14], beyond/to the right of the blue zone, would fortunes transform from dissatisfaction to satisfaction, disengagement to engagement, imbalance to balance $(\approx)$. Importantly, too, job attitudes like job satisfaction and work engagement have links to productivity, both individual [15] and organizational [16], within and between economies [17,18]. 
Organizational case studies suggest that raising legal minimum wages toward QoLW levels does not necessarily result in a reduction of jobs, may improve retention [9,19] and bring efficiency gains to productivity [20]. Nonetheless, case-based evidence to date [21-23] has not been persuasive enough to influence most employers to choose to pay the national or regional campaign living wage [24]. In addition, at a community level, households are diverse, which may render "real" or impactful living wage values variable rather than fixed [10]. Thus, without knowing the relationship between different wage values $(x)$ and quality of work life (y), critics and doubtful employers continue to argue that the value should and could be higher or lower, between continuous and dotted blue lines in Figure 1.

Empirical evidence has recently explored this relationship across two economic and cultural contexts. Recent survey evidence from NZ and South Africa [25] - two arguably very different societies (on population levels, inequality index, GDP, cultural groups, and a range of other variables, for details see [25] - found that the relationship between income and QoLW resembles most closely the blue dotted line in Figure 1. Most organizations in New Zealand and South Africa (SA) were not living wage employers. Yet, there was a transformation from negative to positive valence, on job attitudes like job satisfaction, when wages and income climbed above NZ\$20 per hour and 12K SA Rand per month, respectively. These values approximated their respective campaigned Living Wage rates at the time. Additionally, they were reasonably close in terms of Purchasing Power Parity dollars (PPP\$), when converted to a monthly rate, namely \pm PPP $\$ 2000$ [25]. This closeness may indicate robustness in the PPP\$ figure [25]. However, the transformation was more dramatic (sharper cusp upwards) in SA, where societal inequality was higher.

We must also consider the complexities of household composition and income sources when considering the consequences of living wages for addressing poverty. Demographic research from one recent review indicates three main contributors to in-work poverty: low earnings, labour participation in the household, and number of dependents [26]. Yet Living Wage campaigns have tended to assume a set household configuration and number of incomes, which are then coupled with cost-of-living figures to calculate an hourly rate required to buy essential commodities for that fixed household unit [27,28]. In NZ, for instance, the campaign rate has assumed a household of four people, comprising two adults and two dependent children, with two adult income streams, one full-time and one part-time to care for those children [29]. Critics argue that, as family size and household income naturally vary across households, any living wage value too will vary, as costs of living co-vary with both variables.

This study sets out to explore empirically the link between household characteristics, personal wages, and an employee's quality of work life, through the prism of salient Job Attitudes [10]. In work and organizational psychology, these are standard indicators of quality of (work) life [10,30]. 
As Figure 1 points out, we need to ask not only "what" individual wage figure enables people to experience a Quality of (work) life, which would indicate a Quality-of-Living Wage (QoLW in Figure 1), but also whether that QoLW value fluctuates with different sizes of household unit and amounts of household income. Logically and conceptually, the value of this household income would have to be calculated net of personal wage, i.e., over and above personal wage, since the same variable cannot be counted twice in any such test of moderation. In other words, we cannot have personal wage appearing as both predictor of quality of work life and as a moderator of that linkage.

It is important to determine this threshold empirically, first-andforemost by charting the relationship between income and Quality of (work) life to explore what shape(s) of function results. Figure 1 offers the idea of a wage spectrum to calibrate at what point, if any, people's job satisfaction and other job attitudes (indicative of not feeling trapped in working poverty) begin to improve ( $\approx$ ). Specifically, we probe whether (1) household dependents and income, net of individual wage, would alter the point of inflexion or (2) the gradient of the curve. The latter is a question of moderation, by household income, of personal living wage-and validity of "one" living wage. It is also a question that bears directly on the SDGs, and in particular on the links between SDG-8-Decent Work and Economic Development, and the primary SDG-1-Eradicating poverty in all its forms everywhere [3].

\section{METHOD}

\section{Participants}

A total of $N=1011$ eligible participants were drawn from a nationallyrepresentative, survey panel of lower income workers in NZ, who were paid under NZ\$60,000 per annum [24]. By income level, the majority (39.4\%) came from the NZ\$40,001-60,000 band, closely followed by the NZ\$20,001-40,000 band (35.9\%), and then the up to NZ\$20,000 band (24.7\%).

Demographically, the respondents were more likely to be female (69\%), with age ranging from the early 20 s to over 60 years. The average age category was in the 30-35 age range. Weekly hours worked ranged from 10-50+, with the average in the 26-30 category. By ethnicity, $61 \%$ were NZ European, with the remainder Māori (11\%), Asian (11\%), Indian (7\%), Pacific (6\%), and $3 \%$ other. At the firm level, $68 \%$ of respondents were from the private sector, followed by $18.1 \%$ from the public sector, and $14 \%$ from the not-for-profit sector. Respondents worked in firms of various sizes, with the largest group (28\%) located in micro-sized firms (1-10 employees), and the average firm size being 50 employees. A number also worked in larger firms, including those with more than 5000 employees (9\%). These proportions were reasonably representative of the lower-end of the wage spectrum and economy in NZ [24]. 


\section{Measures}

In addition to a range of standard demographic items, we focused on two particular sets of variables, reflecting (i) income level and (ii) job attitudes.

Income Level. In keeping with the goals of the study (above), income was assessed at both individual and household levels [26]. For individual income, we asked for annual income before tax (open-ended), plus for annual income before tax (in increments of NZ\$5000), and for hourly rate of pay (if paid by the hour); for household income, we asked for total annual income before tax ("yours and that of your partner/family members"), using increments of NZ\$5000).

Job Satisfaction. This construct was measured using three items from Judge and colleagues (2005), coded $1=$ strongly disagree through to $5=$ strongly agree. A sample item includes "I feel fairly satisfied with my job". This measure has been validated in New Zealand samples [31,32], and had excellent reliability in the present study ( $\alpha=0.91$ ).

Work Engagement. This construct was measured using a 9-item measure developed by Schaufeli and colleagues (2001). Our measure used a 5-point frequency scale that ranges from Never to Everyday (for details, see [24]). An exemplar item is "I am enthusiastic about my job". In the present study, across nine items, $\alpha=0.92$.

Career Satisfaction. This was assessed using a 3-item measure developed by Greenhaus and colleagues [33]. The measure utilises a 5-point scale from strongly disagree to strongly agree. An examplar item is: "I am satisfied with the success I have achieved in my career/work". In this study, $\alpha=0.85$.

Meaningful Work. This is a 3-item element in the measurement of workplace empowerment, developed by Spreitzer [34]. The 5-point scale ranges from strongly Disagree to Strongly Agree. An exemplar item is "The work I do on this job is meanfingful to me”. For this study, $\alpha=0.93$.

Affective Commitment. This is the main attitudinal component in the measure of organizational commitment developed in Meyer and colleagues [35]. There were three items, on a scale ranging from strongly disagree through to strongly agree. An examplar item is: "I really feel as if this organisation's problems are my own”. In this study, $\alpha=0.78$.

Organizational Citizenship Behaviors (OCBs). These were measured using a four-item measure [36] targeting the organizational dimension. The scale ranged from strongly disagree to strongly agree. An exemplar item is "I take action to protect the organisation from potential problems". In this study, Coefficient $\alpha=0.84$.

Work-Life Balance was measured using a 3-item measure by Haar [31] which was coded $1=$ strongly disagree to $5=$ strongly agree. A sample item is: "Nowadays, I seem to enjoy every part of my life equally well". This construct has been well validated [12,24,37,38], including cross-culturally [32], as well as in daily diary studies [39], showing it to be a valid and useful 
construct for understanding work-life balance. The measure had very good reliability in this study $(\alpha=0.88)$.

\section{Procedure}

The project was funded by the Royal Society of NZ (RSNZ) through its Marsden Fund (17-MAU/137), and secured ethical approval from Massey University's Northern Human Ethics Committee [40]. The survey was designed by the authors and distributed via a private research company, Qualtrics, which collected the data. Within Qualtrics panel protocols, all participants were assured of confidentiality and remained anonymous to the researchers. Qualtrics pays respondents for their time, but the nature of this arrangement is proprietary. The Qualtrics system had an estimated time for the survey (10 $\mathrm{min}$ in this example), and removed respondents who completed the survey too quickly or too slowly. It also ensured that each respondent can only complete the survey once. We utilized this approach specifically because Qualtrics can target income level in their respondent recruitment, and because their respondents are already familiar with survey formats. During piloting, lack of such familiarity had been identified as a potential barrier to participation by lower-income groups.

\section{Measurement Models}

We confirmed our constructs using CFA with AMOS version 25, using three goodness-of-fit indices by Williams et al. [41] to assess the data: (1) the comparative fit index (CFI > 0.95), (2) the root-mean-square error of approximation (RMSEA < 0.08), and (3) the standardized root mean residual (SRMR $<0.10$ ). Table 1 shows the CFA and comparison models.

Table 1. Results of confirmatory factor analysis.

\begin{tabular}{cccccccccc}
\hline & \multicolumn{4}{c}{ Model Fit Indices } & \multicolumn{5}{c}{ Model Differences } \\
\cline { 2 - 10 } Model & $\boldsymbol{\chi}^{2}$ & df & CFI & RMSEA & SRMR & $\Delta \chi^{2}$ & $\Delta$ df & $\boldsymbol{p}$ & Details \\
\hline Model 1 & 1301.9 & 328 & 0.95 & 0.05 & 0.05 & & & & \\
Model 2 & 1920.5 & 334 & 0.92 & 0.07 & 0.06 & 618.6 & 6 & 0.001 & Model 2 to 1 \\
Model 3 & 2811.0 & 334 & 0.88 & 0.09 & 0.09 & 1509.1 & 6 & 0.001 & Model 3 to 1 \\
\hline
\end{tabular}

Model 1: Hypothesized model: Job Satisfaction, Work Engagement (higher order construct of vigour, dedication and absorption), Career Satisfaction, Meaningful Work, Affective Commitment, OCBs, Work-Life Balance.

Model 2: Alternative model: as model 1 but with Job Satisfaction and Career Satisfaction combined.

Model 3: Alternative model: as model 1 but with MFW and WLB combined.

Overall, the hypothesized measurement model was the best fit for the data (both samples) and this was confirmed by testing several alternative CFA models and these were all significantly poorer fit (all $p<0.001$ ) to the data [42]. 


\section{Analysis}

Consistent with previous analysis protocols in this field [14], we first checked for a statistically significant relationship between personal income (two open-ended questions, above) on the one hand, and worker job attitudes on the other (Figure 1). Converging with previous tendencies in lower-income samples [14,24], more participants responded to hourly rate of pay $(n=722)$ than to annual income options $(n=629)$. Therefore, we computed hourly rate of pay as the predictor variable and job attitude mean scores per item (above) as the criterion, in our initial, relatively smoothed curve estimations.

Curve estimation analyses were conducted in SPSS, exploring three main possibilities: linear; logarithmic and cubic relationship, as suggested in Figure 1 (straight line, diminishing returns, and poverty trap, respectively).

These analyses consistently revealed that there was a statistically significant relationship between hourly rate of pay and job attitudes $(p<0.001)$. The strongest relationship was reliably cubic rather than either logarithmic or (weakest of all three) linear (Figure 1). Specifically, hourly rate of pay accounted for $6.4 \%$ of the variance (uncorrected) in a cubic relationship with job satisfaction $\left(F_{3,591}=13.65\right)$; for $3.8 \%$ of work engagement $\left(F_{3,608}=7.92\right)$; for $9.2 \%$ of career satisfaction $\left(F_{3,591}=19.94\right)$; for $6.8 \%$ of meaningfulness in work $\left(F_{3,591}=14.36\right)$; for $5.1 \%$ in affective commitment $\left(F_{3,591}=10.50\right)$; for $5 \%$ of OCBs $\left(F_{3,424}=7.47\right)$; and for $3.1 \%$ in Work-Life Balance $\left(\left(F_{3,591}=6.36\right)\right.$. These variances are small, and the data noisy, but the initial aim was not to explain variance but to explore any underlying relationship. On that basis, we then proceeded to explore in more detail whether and how these linkages were potentially moderated by (a) number of household dependents and (b) other incomes in the household.

\section{RESULTS}

With respect to the number of household dependents, an initial frequency count of the numbers of dependents revealed that the distribution of numbers of dependents per household was skewed toward none ( $n=665$ respondents) and between one $(n=165)$ or two $(n=123)$, rather than larger households with three dependents $(n=36)$, four $(n=18)$, five $(n=2)$, and six or more $(n=2$, total valid $N=1011)$. Initially, we had hoped to replicate the use (from [25]) of Locally Estimated Scatterplot Smoothing (LOESS) to explore moderation in the shape of the function linking individual income to job attitudes, by different numbers of dependents. With the $n$ in some cells being too small to make meaningful comparisons, we chose instead to utilise MANOVA (Multiple Analysis of Variance). Individual income (in brackets of NZ\$5000) was one independent variable $(N=1011)$, number of dependents was the second independent variable, and job attitudes provided the criterion variables 
(There were 13 respondents who checked a personal income over NZ $\$ 60,000$, even though they had indicated at screening that they earned less. They were therefore excluded from subsequent analyses).

Moderation would be signalled by a statistically significant interaction between the main predictor variables (personal wage and the number of household dependents). MANOVA revealed that there was a borderline multivariate main effect of (i) personal income-band $\left(F_{77,3908}=1.21\right.$, $p=0.10$, partial eta-squared $=0.02$ ) and (ii) number of children living in the household $\left(F_{259,4498}=1.13, p=0.08\right.$, partial eta-squared $\left.=0.06\right)$. At univariate level, however, there were no effects from the number of children $(p>0.90)$, and no significant or borderline significant interactions between income and number of children on any job attitude $(p>0.23)$. As a set, therefore, these findings for household size suggested that number of children in a household was at best a minor moderator of the living wage function in Figure 1.

Although campaign living wage calculations in NZ focus on child dependents (see Introduction), we also asked about the number of "other adults" living in the household ("adult children, other family, friends, living with you"). This question too was not a moderator of the link between personal income and job attitudes, nor did it moderate when added to the number of children living in the household. These other adults in the household might have been earning incomes of their own, of course. Hence, we turned to those other incomes more directly, by creating a new variable, household income net of personal income, which our Introduction noted meant that we had to calculate the household income apart from personal participant wage.

This variable was therefore computed by converting NZ\$5000 categories (for both personal income and household incomes) to an interval scale from 1 to 12, and subtracting the former from the latter, to derive a household-income-net-of-personal income score (Households with combined incomes over NZ\$60,000, which scored $13+$ on the band score, were converted to value missing, in order to keep each variable, personal income and household income, on equivalent scales). Any negative values (household gross income less than individual net, which would not be possible, $n=16$ ) were removed from subsequent analyses. In order to convert the derived interval scale score, which was continuous, to a discrete moderator variable, a median split was used. This created a low $(n=304)$ versus high $(n=310)$ buffer variable, with a total usable $N=614$. Split-file was then applied in SPSS to produce separate LOESS curves for each half of the net-household income group, for each job attitude as a function of hourly wage, at the individual level, by utilising a protocol in Carr et al. [25]. Applying this protocol to determine the point at which the curves were neither too smooth nor too jagged, the tension parameter was eventually set to 0.40 , and the kernel function was Epanechnikov. The resulting LOESS curves, two graphs for each of the job attitudes that formed our criterion variables, are presented in Figure 2. 
From Figure 2, a clear and relatively self-evident pattern can be discerned. Overall, there is a pattern of flat-rise-rise, which replicates previous research [25]. For lower household incomes net of personal income, the curve resembled more clearly the poverty trap function in Figure 1. In the relatively higher household incomes net of personal income, the shape was visibly smoother, in general signifying a less dramatic poverty trap. In each group, however, scores began to climb, and to rise above the mid-point on quality of work life, only beyond the Minimum Wage (NZ\$15.75/hour), and toward the campaign living-wage value in New Zealand at the time (NZ\$20.55). Beyond that point/range of inflexion, there is a second relatively flat section of the curve, a "pause" in the pattern above, which again replicates previous research in this domain [25]. Thereafter, there are clearly diminishing marginal returns [14].
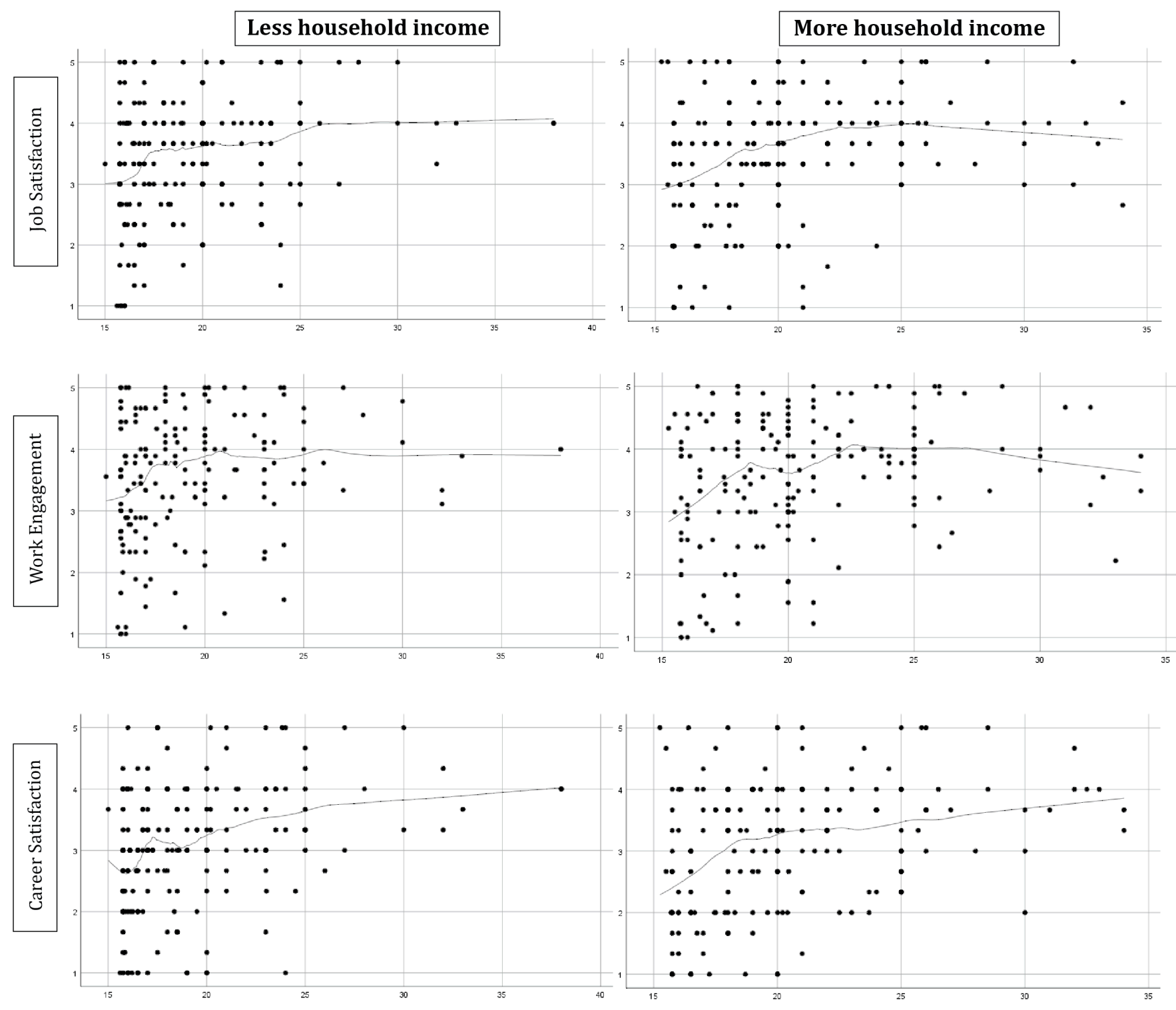

Figure 2. Job attitudes as a function of personal $\times$ household income. 

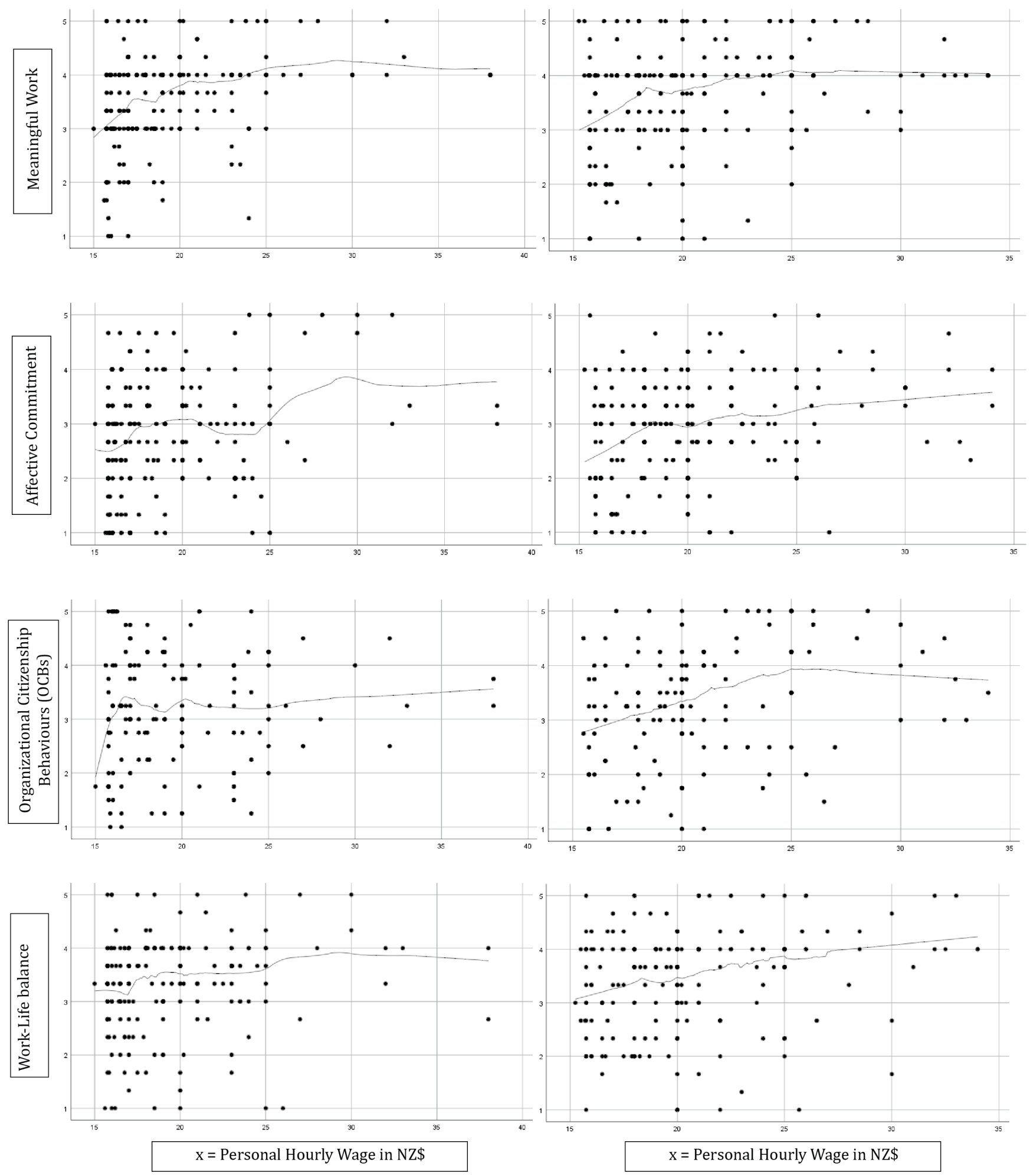

Figure 2. Cont.

Summing up, whilst number of dependents mattered less for the linkage between employee wage and quality of work life, reflected in job attitudes, other incomes may have mattered more, not by changing the actual value of a living wage but by enhancing its transformational value (for quality of work life). 


\section{DISCUSSION}

Living wage debates have arguably struggled to reconcile individual living wages with the diversity of households in which individuals live and which support their work. Econometric means of calculating living wage figures, which rely on cost-of-living surveys, have assumed a particular household configuration, which may not match much of the country [10]. The current study offers a potential way to reconcile an impasse in the critical debate about the validity of the living wage number, by probing empirically how the household factors of child dependents and other income streams, may buffer what counts as a living wage for individual employees.

Specifically, our approach treated household variables as potential moderators of links between hourly pay and job attitudes, which are proxies for perceived quality of work life, and indirectly quality of life more broadly. Using this technique in an NZ context, with a nationally representative sample of low-income workers, we have shown how (and that) child dependents mattered less, and other incomes may matter significantly more, for the quality of (work) life that workers were enjoying. In everyday terms, it seems intuitively obvious that quality of work life (and job attitudes) might negatively relate to number of dependents and positively to household income, as the poorer one becomes, the more generally stressed life may be. However, our results also suggest that one of the linkages is not necessarily as strong as might have been expected-especially perhaps for numbers of dependent children in the household.

As a caveat with respect to dependents, we only sampled from relatively small numbers of household dependents. Logically there would be a point at which large household sizes, in which there were no other income streams, would experience pressures and insecurities to maintain Quality of living and potentially QoLW (in Figure 1). This could occur for example through life-work interference, by worrying about feeding the household and paying household bills. At that point, for such a relatively special case of large household and low number of household incomes, the number of dependents could logically be expected to moderate the links between individual wage and personal job attitudes. We did find some slight signs of such potential moderation in the current study, across job attitudes as a set (see also [26]).

With respect to other income net of personal wages, individuals living in single income households, and particularly if they were paid at or near to the legal Minimum Wage, experienced a sharper poverty trap, as well as a more dramatic transformation in quality of life and work life, from crossing the living wage threshold. Our study was conducted in one economy, in NZ, but at least one other study, in Hong Kong, found that number of dependents did not tip households into working poverty, in the way that low wage and fewer other incomes in the household (especially being a single-earner) did [26]. Thus, our findings are consistent with other 
research, and connect that research specifically with the living wage (and living wage value).

In terms of living wage theory, our data are more consistent with poverty trap theory than with either classical linear models of payattitudes linkages [43], or with theories of Diminishing Marginal Returns (for a review, see [10]). The shape of the functions that we obtained for job attitudes (in Figure 2) were closer on the whole to the sigmoidal, $S$-shaped line (in Figure 1) than to either a straight line or logarithmic curve. The finding of second pause in the curve, once hourly pay exceeds the campaign Living Wage, was consistent with previous research as well as with the Theory of Relative Deprivation [25]. Specifically, having surpassed the living wage threshold in Figure 1, expectations and frames-of-reference may have risen toward the upper end of the wage spectrum [10,14].

In terms of fitting with sustainable development, these findings have relevance for sustainable development policy. Specifically, Sustainable Development Goal 8 calls for Decent Work and Economic Development, whilst SDG-1 is to reduce poverty in all its forms everywhere, including working poverty and poverty in higher-income economies [3]. The concept of a living wage threshold, beyond which job attitudes become more positive than negative, suggests a link between the twin targets (and a potential win-win). In the wider literature that is, increases in job satisfaction and organisational commitment have been widely and substantively linked, with increases in both individual- and unit-level productivity, across a range of socio-cultural and socio-economic contexts [16-18,35,44,45]. Thus research on living wages can contribute to the achievement of the SDGs, including shared prosperity for all through decent work and economic development.

These previously demonstrated linkages have shown themselves to be especially strong when job attitudes combined into a single model as a set (see [15,46]). Efficiency Wage Theory then suggests that crossing a living wage threshold can be experienced by employees as being valued by employers and is capable of resulting in a qualitative rise in productivity levels [47-49]. Indeed, in other research, we found that working for a living wage employer brought a significant boon to job satisfaction [24]. Thus, a living wage has the potential, through job attitudes, to link to higher productivity, for which meta-analytic support exists [50]. Along with other variables above (e.g., workplace size, job characteristic and type, skills usage, autonomy, etc., above) it would thereby contribute towards both facets of SDG-8, decent work and economic development, marking the beginnings of an SDG-focused business case for living wage values [51,52].

This study is not without its limitations. With respect to child dependents in the household, a larger sample and sub-samples per income bracket, would have allowed us to use LOESS rather than the cruder MANOVA test for cusps in the income-attitudes function. Future research 
may also explore larger household sizes than we managed to capture, since at some point, larger numbers of dependents and small numbers of income will logically start to bite. Our sample though representative did not capture such extreme configurations. Similarly, at the other extreme of household size, we can envisage single parent households in which income-earning potential is constrained due to child-care needs and responsibilities. Such configurations may further vary by gender, and thereby relate to gender equity (SDG-5). Future research will explore this possibility.

In terms of generalizability outside of the NZ economy and labour market, we would highlight some specificities of the study's context. For example, a discussion of the living wage needs to locate the notion in the context of the tax and transfer system and the quality of welfare state services and infrastructure specific to the country and how these affect household income and wellbeing. It could make a world of difference how much an individual's wage has to pay directly for education and health services compared with being free, the extent to which these rights are available and the quality of the country's public infrastructure. If there are high marginal tax rates for individuals it affects the extent to which a higher wage corresponds to access to services. For instance in Australia a higher household income will affect the level of the child care subsidy.

Similarly productivity is a very complex phenomenon with a large literature attached, with worker morale a dimension which this paper importantly feeds into. Higher wages (and here, wellbeing) may boost productivity and vice versa. A different view is that workers and worker effort plays little role in determining productivity which is fixed technologically by relationship between inputs. This view remains to be tested in the future of work.

All of our data were concurrent, and it would also be informative, for purposes of determining income mobility, to have a longitudinal sample. However, in NZ labour law reform, efforts are being made to determine whether major increases in the legal minimum wage, from NZ\$16.50 in 2018 to NZ $\$ 17.70$ in 2019, NZ\$18.80 in 2020 and NZ\$20 by 2021 [53] currently being implemented in stages between now and 2021, will make a difference to achieving SDG-8 in New Zealand, for example, by accelerating low-paid workers' escapes from (working) poverty traps (Figure 1). It remains for other studies in this field to explore this possibility empirically and over time. For example higher wage countries' firms and economies are relatively sustainable and might be more so to the extent that wellbeing is increased through living wages that they are more able to afford in the first place, for example through relatively slack resources. Such questions of sustainability are set to be tested in our project and across collaborative networks globally [52].

In conclusion, the findings reported in this study suggest a novel and substantive empirical way to bolster living wage policies as a means to sustainable livelihood and shared prosperity, across employees, their 
households and employer groups. The study remains exploratory and is anchored in one particular context-the NZ economy and society. For example, NZ is a small economy and has a relatively specialised labour market, with service-sector emphasis rather than heavy industry structure, reliance on small to medium enterprises, and being a trading dependent nation. Such factors may clearly have implications for the generality or otherwise of the findings.

Nevertheless, this application of a multi-level approach, in which households and workplaces are intersecting domains, and where level 2 household variables moderate the linkages at level 1 (individuals), between pay and quality of (work) life, marks what we perceive to be an interdisciplinary step towards decent work and economic development for all, with a potential to extend to other contexts and measures than job attitudes.

\section{DATA AVAILABILITY}

The dataset of the study is available from the authors upon reasonable request.

\section{AUTHOR CONTRIBUTIONS}

SCC conceptualised the paper, devised and ran the moderation and curvilinear analyse, and drafted the paper. $\mathrm{JH}$ completed the data reduction, including exploratory and confirmatory factor analyses. DH, JA, JP, AYH, SAT and HJ edited the draft paper. HJ edited the graphic figures.

\section{CONFLICTS OF INTEREST}

The authors declare that there is no conflict of interest.

\section{FUNDING}

We gratefully acknowledge the support of a grant (17-MAU-137) from the Royal Society of New Zealand (RSNZ), without which this research would not have been possible.

\section{ACKNOWLEDGEMENT}

We are grateful for the participation of our respondents and expert advisors, including Pa Nephi Skipwith and William Cochrane, and for the fruitful collaboration with Qualtrics, as well as the support of our respective School and Department, and respective University research colleagues.

The key advice and constructive input of our peer reviewers and editors are gratefully acknowledged and appreciated. They significantly improved the quality of the article, and in parts have been incorporated verbatim. 


\section{REFERENCES}

1. Global Commission on the Future of Work. Work for a brighter future. Geneva (Switzerland): ILO; 2019. p. 3.

2. Eurofound (European Foundation for the Improvement of Living and Working Conditions). Labour market change: Concept and practice of a living wage. Luxembourg (Luxembourg): Eurofound; 2018.

3. United Nations. Sustainable Development Goals-Knowledge Platform. New York (US): United Nations; 2019.

4. ILO. World Employment Social Outlook: Trends 2018. Geneva (Switzerland): ILO; 2018.

5. Standing G. The Precariat: The New Dangerous Class. 3rd ed. London (UK): Bloomsbury Academic; 2016.

6. World Inequality Lab. World Inequality Report 2018. Berlin (Germany): World Inequality Lab; 2018. p. 5.

7. ILO. Global Wage Report 2016/7: Wage inequality in the workplace. Geneva (Switzerland): ILO; 2017.

8. ILO. Asia-Pacific Employment and Social Outlook 2018: Advancing Decent Work for Sustainable Development. Geneva (Switzerland): ILO; 2018.

9. ILO. World of Work Report: Repairing the Economic and Social Fabric. Geneva (Switzerland): ILO, 2013.

10. Carr SC, Parker J, Arrowsmith J, Watters PA. The Living Wage: Theoretical integration and an applied research agenda. Int Labour Rev. 2016;155(1):1-24,

11. Yao C, Parker J, Arrowsmith J, Carr SC. The living wage as an income range for decent work and life. Employee Relat. 2017;39:875-87.

12. Haar JM, Sune A, Russo M, Ollier-Malaterre A. A cross-national study on the antecedents of work-life balance from the fit and balance perspective. Soc Indic Res. 2019;142(1):261-82.

13. Maleka M, Rugimbana R, Carr SC, Meyer I, Parker J, Barry ML. Reflections on a study conducted in New Zealand and South Africa to ascertain the extent to which living wages are a panacea for quality life for low-income workers. In: Sage Research Methods Cases Part 2. Thousand Oaks (US): SAGE Publications Inc; 2018. doi: 10.4135/9781526449481

14. Carr SC, Parker J, Arrowsmith J, Haar J, Jones H. Humanistic management and living wages: A case of compelling connections? Humanistic Manag J. 2017;1(2):215-36.

15. Harrison DA, Newman DA, Roth PL. How important are job attitudes? Metaanalytic comparisons of integrative behavioral outcomes and time sequences. Acad Manag J. 2006;49(2):305-25.

16. Harter JK, Schmidt FL, Hayes TL. Business-unit-level relationship between employee satisfaction, employee engagement, and business outcomes: A meta-analysis. J Appl Psychol. 2002;87(2):268-79.

17. Davar SC, Ranju B. Relationship between job satisfaction and job performance: A meta-analysis. Indian J Ind Relat. 2012;48(2):290-305.

18. Jaramillo F, Mulki JP, Marshall GW. A meta-analysis of the relationship between organizational commitment and salesperson performance: 25 years of research. J Bus Res. 2005;58(6):705-14. 
19. Card D, Krueger AB. Minimum Wages and employment: A case study of the fast-food industry in New Jersey. Am Econ Rev. 1994;84(4):772-93.

20. Shambaugh J, Nunn R, Liu P, Nantz G. Thirteen facts about wage growth. In: Economic Facts. Washington, D.C. (US): Brookings Institute, The Hamilton Project; September 2017.

21. Coulson AB, Bonner J. Living wage employers: Evidence of UK business cases. Strathclyde (UK): University of Strathclyde; 2015.

22. A Fairris D, Runsten D, Briones C, Goodheart J. Examining the evidence: The impact of the Los Angeles Living Wage Ordinance on workers and businesses. Los Angeles (US): UCLA; 2015

23. Werner A, Lim M. Putting the living wage to work: Strategies and practices in small and medium sized enterprises (SMEs). Middlesex (UK): Barrow Cadbury Trust; 2016.

24. Haar J, Carr SC, Parker J, Arrowsmith J, Hodgetts D, Alefaio-Tugia S. Escape from working poverty: Steps toward Sustainable Livelihood. Sustainability. 2018;10:4144. doi: 10.3390/su10114144

25. Carr SC, Maleka M, Meyer I, Barry ML, Haar J, Parker J, et al. How can wages sustain a living? By getting ahead of the curve. Sustain Sci. 2018;13(4):901-17. doi: 10.1007/s11625-018-0560-7

26. Cheung KCK, Chou KL. Working poor in Hong Kong. Soc Indic Res. 2016;129(1):317-35.

27. Anker R. Estimating a living wage: A methodological review. Geneva (Switzerland): International Labour Organization (ILO); 2011.

28. Tijdens K, Fabo B. Codebook on WageIndicator web survey on work and wages. Amsterdam (Netherland): WageIndicator Foundation; WageIndicator Data Report, December 2014.

29. King P. Setting the New Zealand living wage: complexities and practicalities. Labour Ind. 2016;26(1):8-23.

30. Sen A. Development as freedom. Oxford (UK): Oxford University Press; 1999.

31. Haar JM. Testing a new measure of work-life balance: A study of parent and non-parent employees from New Zealand. Int J Hum Resource Manage. 2013;24(3):3305-24.

32. Haar JM, Russo M, Sune A, Ollier-Malaterre A. Outcomes of work-life balance on job satisfaction, life satisfaction and mental health: A study across seven cultures. J Vocat Behav. 2014;85(3):361-73.

33. Greenhaus JH, Parasuraman S, Wormley WM. Effects of race on organizational experiences, job performance evaluations and career outcomes. Acad Manag J. 1990;33(1):64-86.

34. Spreitzer GM. Psychological empowerment in the workplace: Dimensions, measurement, and validation. Acad Manag J. 1995;38(1):1442-65.

35. Meyer JP, Allen NJ, Smith CA. Commitment to organizations and occupations: Extension and test of a three-component conceptualization. J Appl Psychol. 1993;78(4):538-51.

36. Lee K, Allen NJ. Organizational citizenship behavior and workplace deviance: The role of affect and cogitions. J Appl Psychol. 2002;87(1):131-42. 
37. Haar J, Roche M, Brougham D. Indigenous insights into ethical leadership: A study of Māori leaders. J Bus Ethics. 2018;10:1-20. doi: 10.1007/s10551-0183869-3

38. Haar J, Roche MA, ten Brummelhuis L. A daily diary study of work-life balance in managers: Utilizing a daily process model. Int J Hum Resource Manage. 2018;29(18):2659-81.

39. Haar J, Brougham D, Roche MA, Barney A. Servant-leadership and work engagement: The mediating role of work-life balance. NZJHRM 2017;17(2): 56-72.

40. MUHEC (Massey University Human Ethics Committee). Living wages: Transforming lives, transforming work? Auckland (New Zealand): Massey University; 2018. Reference: NOR 18/04.

41. Williams LJ, Vandenberg RJ, Edwards JR. Structural equation modelling in management research: A guide for improved analysis. Acad Manag Ann. 2009;3(1):543-604.

42. Hair JF, Black WC, Babin BJ, Anderson RE. Multivariate Data Analysis: A Global Perspective. 7th ed. Upper Saddle River (US): Pearson Prentice Hall Publishing; 2010.

43. Judge TA, Piccolo RF, Podsakoff NP, Shaw JC, Rich BL. The relationship between pay and job satisfaction: A meta-analysis of the literature. J Vocat Behav. 2010;77(2):157-67.

44. Iaffaldan, MT, Muchinsky PM. Job satisfaction and job performance: A metaanalysis. Psychol Bull. 1985;97(2):251-73.

45. Meyer JP, Stanley DJ, Herscovitch L, Topolnytsky L. Affective, continuance, and normative commitment to the organization: A meta-analysis of antecedents, correlates, and consequences. J Vocat Behav. 2002;61(1):20-52.

46. Riketta, M. The causal relation between job attitudes and performance: A meta-analysis of panel studies. J Appl Psychol. 2008;93(2):472-81.

47. Budd JW. Employment with a human face: Balancing efficiency, equity, and voice. Ithaca (US): Cornell University Press; 2014.

48. Stiglitz JE. The efficiency wage hypothesis, surplus labor, and the distribution of income in L.D.C.s. Oxf Econ Pap. 1976;28(2):185-207.

49. Yellen JL. Efficiency wage models of unemployment. Am Econ Rev. 1984;74(2):200-5.

50. Judge TA, Thoresen CJ, Bono JE, Patton GK. The job satisfaction-job performance relationship: A qualitative and quantitative review. Psychol Bull. 2001;127(3):376-407.

51. Zeng Z, Honig B. Can living wage be a win-win policy? A study of living wage effects on employer and employee performance in Hamilton, Canada. In: Phillips R, Wong C, editors. Hand-book of community well-being research. International Handbooks of Quality of Life book series. New York (US): Springer; 2017. p. 575-92.

52. Project GLOW. Global Living Organisational Wage. Available from: http://www.massey.ac.nz/project-glow. Accessed 2019 Jun 21. 
53. Ministry of Business, Innovation and Employment (MBIE). Minimum Wage going up to \$17.70. Wellington (New Zealand): MBIE; 2018.

How to cite this article:

Carr SC, Haar J, Hodgetts D, Arrowsmith J, Parker J, Young-Hauser A, Alefaio-Tuglia S, Jones H. An Employee’s Living Wage and Their Quality of Work Life: How Important Are Household Size and Household Income? J Sustain Res. 2019;1:e190007. https://doi.org/10.20900/jsr20190007 